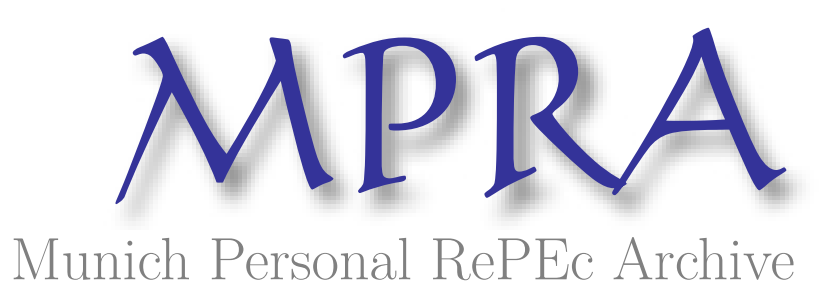

\title{
Inventory and the Shape of the Earth
}

Lai, Richard

Harvard Business School

19 July 2007

Online at https://mpra.ub.uni-muenchen.de/4754/

MPRA Paper No. 4754, posted 07 Sep 2007 UTC 


\title{
Inventory and the Shape of the Earth
}

\author{
MESOM Conference June 19-20, 2006, Atlanta
}

Richard Lai ${ }^{1}$

How important are local country conditions to firms' operations performance, as revealed in their inventory levels? Under a "flat world" hypothesis, differences in firms' inventory levels are explained more by differences among industries and firms themselves, rather than differences among country conditions (e.g., institutions, infrastructure). In a "round earth" hypothesis, country factors out-weigh firm and industry factors. Using all COMPUSTAT observations for manufacturing firms in 70 countries, covering the years 1994 through 2004, we find little evidence for the "round earth" hypothesis. In our baseline model, country effects explain at most $12.7 \%$ of inventory variance, while firm differences explain $35.5 \%$, and industry differences explain $28.5 \%$. This finding is robust to a number of sensitivity tests. Apart from the empirical contribution, this finding can be a useful stylized fact for further theoretical development into the locus of inventory variance. It also has a practical implication - perhaps inventory practices are much more transportable across countries than we have known before.

Keywords: Inventory, flat world, round earth, country effects, firm effects, industry effects.

${ }^{1}$ Harvard Business School, Morgan Hall T47, Boston MA 02163. Tel: (617) 495 6228. Fax: (617) 496 4397, Email: rlai@hbs.edu. 


\section{Inventory and the Shape of the Earth}

\section{INTRODUCTION}

How important are local country conditions to firms' operations performance, as revealed in their inventory levels? ${ }^{2}$

One answer is in the form of a "flat world" hypothesis. It has many variants, but the underlying theme is that firms' inventory levels are dictated more by global conditions (e.g., global demand, global interest rates) than by indigenous conditions (e.g., institutions, infrastructure). In the popular literature--indeed, we take the phrase "flat world" from Friedman (2005) - there is a frequent argument that integrated supply chains across countries means that country-specific factors matter less. In the theoretical literature, it is also the paradigm in much of international economics-usually under the rubric of convergence of productivity or technologies - and international business - where it is sometimes called "global determinism" (e.g., Khanna and Rivkin (2001)). Firms are subject to the overwhelming gale of global forces: foreign competition in the form of imports and foreign firms competing in domestic markets, international learning, the pressures of financial markets.

In contrast, a "round earth" hypothesis says that firms' operational performances are different because they operate under different country conditions. Much of the thinking on

${ }^{2}$ Inventory, of course, is not the only parameter in operations management. We confine our attention to inventory levels to keep this paper tractable and because inventory levels are "commonly used to measure performance of inventory managers, compare inventory productivity across [firms], and assess performance improvements over time" (Gaur, et al. (2005), pg. 181). 
"appropriate technologies" for third-world firms is consistent with this theme (e.g., Basu and Weil (1998)). There are also other reasons offered. For example, Zeira (1998) argues that innovations might be adopted only in countries already with high productivities. Following his logic, firms with innovative inventory management are more likely to be found in some countries than others. Goodfriend and McDermott (1998) suggest that some "economies diverge substantially and persistently" (pg. 1277) because they are not learning much from the global economy (see also Krugman \& Venables (1995)). Bernard and Jones (1996) document evidence that manufacturing technologies do not converge, even among OECD countries.

Given so many variants of these two hypotheses, how does one empirically test whether the earth is "flat" or "round"? We propose one operational definition: in the round earth (null) hypothesis, differences in inventory levels are due more to country differences than to otherssuch as differences in industry or firm. We are not claiming that this is the best definition, only that it is useful and has some theoretical basis. It is certainly useful empirically, since we can now formally test the hypotheses by decomposing and comparing firm-level inventory variance in terms of country, industry, and firm effects. It is also grounded in the theoretical tradition in explaining differences among firms. In section 2, we present our case for considering these three factors--country, industry, firm differences - as explanations for why inventory at the firm level might be different.

In section 3, we link the theoretical discussion to empirical antecedents in operations management. We also discuss methodological antecedents in related fields such as industrial organization and strategy.

In section 4, we describe two methods we use to distinguish the hypotheses. Specifically, 
we employ VCA (variance components analysis) and nested ANOVA (analysis of variance). These methods are standard in the industrial organization and strategy literature (e.g., McGahan and Porter (1999), Rumelt (1991)). Schmalensee (1985)), so we review them only briefly here. There are two key reasons for using these methods, rather than say, regression analyses. The first is that they allow us to identify variances; a standard LSDV (least squares dummy variables) regression would need to cope with the identification challenge involving several thousand indicator variables for firms, industries, and countries on the right-hand side. In other words, the regression would be under-specified. The second reason is that such regressions are computationally expensive, even with the Sun Enterprise V890 to which we have access.

In section 5, we describe how we assemble firm-year data. One of the empirical challenges is to account for the range of accounting standards used across countries. Fortunately, the dataset contains details of standards used. For example, some firm-years are tagged with "accounts reclassified to show allowance for doubtful accounts and/or accumulated depreciation as a reduction of assets rather than liabilities" versus others with "domestic standards generally in accordance with IASC (International Accounting Standards Committee) and OECD guidelines."

In section 6, we report our baseline results. We find that, consistent with a "flat world" hypothesis, country differences have the least explanatory power, compared with firm and industry differences. Country differences explain $12.7 \%$ of inventory differences, while firm differences explain $35.5 \%$, industry differences explain $28.5 \%$, and year differences explain $0.7 \%$. This result for inventory in general also holds for specific inventory types: raw materials, work 
in progress, and finished goods.

In section 7, we subject our analysis to a battery of robustness checks. We use different transformations of the dependant variable (inventory), next-period dependant variables, 3 different treatments of outliers, 9 sub-samples with homogenous accounting conventions in each, 2 time periods, 4 firm size quartiles, and interactions with time. In all cases, our baseline conclusion stands.

In section 8 , we conclude by discussing future work. Our analyses do not answer many other questions. For example, we have not examined the direction of causality, given the limitations of the methods, although this stance is standard in the literature (e.g., McGahan \& Porter (2002)). Nor have we studied the channels through which country, firm, or industry effects affect inventory variance. These are interesting avenues for future research.

The main contribution of this study is to rigorously distinguish the "flat world" and "round earth" hypotheses, using a robust definition that can identify the aggregate class of factors that explain why firms hold different levels of inventory. We believe this can become an important stylized fact in operations management. This finding in turn has important practical and theoretical implications.

On the practical dimension, it explains why we often observe that inventory policies travel well across national boundaries, such as when Toyota operates in the United States. Japanese conditions explain much less about Toyota's inventory policies than the fact that Toyota is Toyota. Also, the magnitude of country effects can point to how strategic it is to locate one's plants overseas or to face a foreign competitor on home ground. For example, if country factors significantly explain operational differences, one interpretation is that they are very strategic, in 
the sense that being in the "right" country could be difficult to obtain, but once obtained, could provide significant advantage for a firm. What we document here is that country differences turn out to be smaller than firm or industry differences. "How much" less strategic this is, of course, is in the eye of the beholder. But given the evidence here, we believe managers do need to think especially hard now about arguments such as those that suggest strategic advantages in operations could be obtained by relocating plants to foreign countries. We must immediately qualify this, since firms could relocate plants overseas for more than just operational reasons, and even then, what we have analyzed here is just inventory, one aspect of operations.

Subject to these same qualifiers, our finding also has important theoretical implications. The most important is that it gives some preliminary assurance that optimization models developed in the U.S. could be reasonably applied to contexts in other countries. Again, this is not to say that no modification is needed. Instead, we are saying that with country differences at three times less than the explanatory power of firm differences, and two times less that of industry differences, they matter surprisingly less than we have thought. It is not obvious before this study, for example, to think that country factors like institutions and infrastructure explain five times less than the combined firm and industry factors.

Another implication of our finding is its connection to recent empirical studies. For example, Gaur, et al. (2005) show that several firm-specific factors such as capital intensity and gross margin account for $97.2 \%$ of inventory differences, after controlling for industry. This would have been less interesting if firm factors account for a small percentage of inventory differences. As it turns out, our finding suggests that their result is of utmost importance, since firm factors, and not country or industry factors, do account for large chunk - at least a third - of inventory 
heterogeneity. ${ }^{3}$ We discuss these implications further in our last section.

\section{COUNTRY, INDUSTRY, AND FIRM EFFECTS}

As explained, we couch the "round earth" null hypothesis as one in which inventory variance among firms could be better explained by country rather than industry or firm differences. We draw on three streams of literature on country, industry, and firm explanations.

The first is that countries matter. It is implicit in many discussions of supply chains that idiosyncratic elements in other countries are indigenous fixtures that have to be worked around. Examples of these include Japan's hansha's (販社 ${ }^{4}$, or exclusive distributors used by companies such as $\mathrm{KaO}^{5}$ or National Bicycle as described in Fisher (1997)) or Italy's impannatore in its "Prato system" (see Jaikumar (1985)). Supporting this view is the very large literature from institutional economics (e.g., North (1990)) and law and finance (e.g., La Porta, et al. (1998)) that argue for the wide-ranging impact of country-specific factors. To the extent that supply chains and key aspects of inventory management-such as the cost of capital and financial constraints-are influenced by such factors, we expect that country differences loom large in explaining why foreign firms' inventory levels and trends are different from those in say, U.S. firms.

The second possibility is that industry is the dominant explanation. This parallels the

${ }^{3}$ An important qualifier is that Gaur, et al. study retail industries, while we look at manufacturing industries here. We are currently working on a retail dataset.

${ }^{4}$ The full name for such distributors is hanbai kaisha (販売会社).

${ }^{5}$ See http://www.kao.co.jp/en/company/history/1990c.html 
analogous view called "industry analysis" in the strategy literature (e.g., Porter (1980)) or "industrial organization" in economics (e.g., Caves (1974)). In this view, performance is primarily dependant on industry-level factors such as entry barriers, market share, and the number of competitors. Firm-specific differences may be present in a cross-section, but are eroded through competition (e.g., Jovanovic (1982)). In equilibrium, what remain as explanations for differences in firm inventory levels are industry factors such as key aspects of a supply chain, like the number and power of customers and suppliers, or how competitive is the industry to keep service levels up.

The third possibility is that firm differences is the dominant explanation. This too has foundations in economics, chiefly propounded by Demsetz (1973). In the strategy literature, it is most closely associated with the resource-based view (e.g., Amit and Schoemaker (1993), Barney (1986), Dierickx and Cool (1989), , Rumelt (1984), Wernerfelt (1984)). In this view, firm differences - such as superior operations management or privileged access to suppliers-that are valuable, scarce, inimitable, non-substitutable, are the primary determinants of operational performance. Weak firms perform poorly in attractive industries and strong firms can thrive in unattractive ones.

\section{EMPIRICAL ANTECEDENTS}

Our research question builds upon a number of empirical papers that shed light on what explains inventory policies. The majority of these papers seek to explain inventory variance in terms of firm differences, rather than industry or country differences.

We have mentioned Gaur, et al. (2005). The thrust of their study is to uncover firm effects, within the retail industry. Lieberman, et al. (1999) study the automotive supplier industry and 
find that inventory variance can be explained by differences in technological factors like lead time and managerial factors like employee activism in problem-solving. Netessine and Roumiantsev (2005a) report that inventory variance can be explained by differences in parameters in classical inventory management models. Still other papers explain cross-industry variance in terms of specific inventory programs. For example, Balakrishnan, et al. (1996) report that, for a sample of 46 manufacturers, some inventory variance could be explained by firms' implementing just-in-time (JIT) or total quality management (TQM) processes (see also Alles, et al. (2000), Hendricks and Singhal (1997), Lieberman and Demeester (1999), Sakakibara, et al. (1997), Schultz, et al. (1999)). Hendricks and Singhal (2005) document how inventory differences could be due to supply chain disruptions. Finally, there are others who study inventory-reducing programs within industries, but it seems quite clear that their findings have broader impact, outside their industries of study. For example, Hopp, et al. (1997) propose a number of control policies that can reduce inventory levels by $20-25 \%$ without sacrificing service levels. Others include the Fisher and Ittner (1999) study of General Motor's Delaware plant, the work of Iyer and Bergen (1997) and Raman, et al. (1997) on quick response systems in the apparel industry, and the Kapuscinski, et al. (2004) study of the Dell supply chain. This paper is also related to Lai (2006a), who show that firm effects dominate over industry effects in explaining inventory. That study does not consider country effects. Taken together, we get the impression that firm effects are strong, and industry effects are weaker if improvements in one industry are portable to another.

Finally, there is a sub-discipline of international operations management, but the empirical work there is mostly case-based or survey-based (but see Lai (2006b)). For example, Chikan and 
Whybark (1990) survey firms in South Korea, China, Western Europe and Hungary and conclude that more industrialized countries have lower inventory. Prasad and Babbar (2000) and Prasad, et al. (2001) carry good guides to these works. The premise underlying these papers tends to be consistent with the country effects explanation.

To summarize, none of the studies mentioned above is designed to answer the question of how much country effects explain inventory variance. ${ }^{6}$

We now turn to the literature on methods. Here, a very large number of papers have developed a strong tradition, focused on explaining not inventory variance but variance in financial performance, typically measured using return on assets (ROA). Schmalensee (1985) is generally credited with the first study. Some widely-cited papers in this stream include Bowman \& Helfat (2001), Brush \& Bromiley (1997), McGahan \& Porter (1997), McGahan \& Porter (2002), Roquebert et al. (1996), Rumelt (1991). All study the question of whether firm or industry effects are larger, rather than country effects. The exception is Makino, et al. (2004), who look at the performance of Japanese MNC (multinational) subsidiaries in 79 countries. They find that country effects explain $4 \%$ to $8 \%$ of differences in ROS (return on sales). They interpret these as "strong," but only as relative to the weak industry effects, which also have explanatory power in the single digit percentages. The relevance of these papers to us is that they provide guidance on sensitivity tests. We describe them in detail in our section on

6 There is also a literature on inventory in economics. However, this focuses on inventory cycles, especially as explanations of business cycles. Blinder (1981) and McCarthy and Zakrajsek (2002) are good surveys. Also, there is a large literature on production efficiency (e.g., Caves (1992) and Jorgenson (1988)). 
robustness tests.

\section{METHOD}

We first describe the model to be estimated, and then two methods to do the estimation.

The baseline model is as follows:

$$
i_{c, n, f, t}=\mu_{\ldots .}+\alpha_{c}+\beta_{n}+\gamma_{f}+\delta_{t}+\varepsilon_{c, n, f, t},
$$

where $i_{c, n, f, t}$ is inventory (scaled by cost of goods sold) of firm $f^{\prime}$ s inventory over year $t$ when it has primary industry $n$ at the NAICS 6-digit level and is located in country $c ; \mu \ldots$ is a constant for the overall mean effect with the three dots denoting averaging over the three indices, $\alpha_{c}$ the country effect, $\beta_{n}$ the (primary) industry effect, $\gamma_{f}$ the firm effect, $\delta_{t}$ the year effect, and $\varepsilon_{c, n, f, t}$ is an $\mathrm{AR}(1)$ process (see below). We use just the primary industry for the practical reason that we do not have information on industry diversification. To the extent that there are corporateparent effects that we do not model, our finding of small country effects is further strengthened.

Following the literature, we estimate equation (1) using two primary methods: VCA and nested ANOVA. Because these have been extensively discussed by the papers cited earlier, we do not describe them in detail here. VCA may be less familiar to some researchers, so we provide a brief summary in the Online Appendix. We also refer interested readers to Searle, et al. (1992) for a textbook treatment. Here, we highlight just the few salient points about these methods.

First, with thousands of variables on the right-hand-side, the individual effects are not identifiable without an enormous number of observations. The econometric problem here, however, is to estimate only the intercept and five (including the error term) variances on these effects. Second, it should be clear that the methods, while able to cope with identification with 
many variables, cannot rigorously identify causality. Following the empirical literature, we focus on the issue of locus-i.e., the size of the effects, however generated, that explains inventory variance. We do, however, attempt to shed more light than is normal in the literature by employing next-period dependent variables (please see robustness section). Third, the difference between VCA and nested ANOVA is that the former assumes random effects, in that processes generating the effects are not correlated with the levels of the effects ${ }^{7}$. Nested ANOVA does not use this assumption, but it suffers the disadvantage that the order with which the effects enter the model matters. Finally, we are concerned about serial correlation of shocks. Following McGahan and Porter (1997), we include an AR(1) model for the error term:

$$
\varepsilon_{c, n, f, t}=\rho . \varepsilon_{c, n, f, t-1}+\eta_{c, n, f, t}
$$

where the $\eta_{f, i, t}$ is white. This transforms equation (1) into:

$$
i_{c, n, f, t}=\rho \cdot \dot{i}_{c, n, f, t-1}+(1-\rho) \mu \ldots .+(1-\rho) \alpha_{c}+(1-\rho) \beta_{n}+(1-\rho) \gamma_{f}+\left(\delta_{t}-\rho . \delta_{t-1}\right)+\eta_{c, n, f, t}
$$

The variance model when using nested ANOVA is straightforward:

${ }^{7}$ As McGahan and Porter (2005) point out in a paper summarizing the decades of research in this field, this assumption is "often misconstrued" (pg. 874) and is a lot weaker than often assumed. Technically, it only means that there is no relationship between the sizes of the effects on an observation and the frequency with which these effects are generated and their sizes. "It is worthwhile to reflect on the fact that the original VCA by Schmalensee (1985) did not depart from historical precedent...VCA identifies the first-order influence of the classes of effects and apportions variance between them. Without additional information, it is not unreasonable to make a first-order approximation of the decomposition of variance under the assumption that the relationships are randomly conferred." (pg. 877). 


$$
\sigma^{2} i=(1-\rho)^{2}\left(\sigma^{2} \alpha+\sigma^{2} \beta+\sigma^{2} \gamma\right)+\left(1+\rho^{2}\right) \sigma^{2} \delta+\sigma^{2} \eta
$$

where the left-hand side is variance of $i_{c, n, f, t}-\rho . i_{c, n, f, t-1}$, the inventory that is not influenced by shocks in the previous year (see McGahan and Porter (1997)).

\section{DATA}

We use all 71,203 annual firm-year observations in the COMPUSTAT tapes, for years 1994 through 2004 and for the manufacturing industry (NAICS codes 31 through 33). Following Chen, et al. (2005), we limit our investigation to manufacturing firms because inventory could have very different interpretations in non-manufacturing firms. There are 9,617 unique firms from 70 countries. COMPUSTAT claims that the dataset covers "over $90 \%$ of the world's market capitalization, including coverage of over $96 \%$ of European market capitalization and $88 \%$ of Asian market capitalization."

For firms that restate their numbers, we use the restated figures. To deal with outliers, we winsorize the data at $1 \%$ and $99 \%$, as is standard in the financial economics literature - e.g., Gompers, et al. (2005). We defer description of robustness analyses - such as addressing the treatment of outliers - to a later section.

The resulting dataset is summarized in Table 1. In panel (a), we show the median inventory levels of all firms. In panel (b), we report the distribution of observations by year; in panel (c), by country; and in panel (d), by 3-digit NAICS industry code (the dataset uses the full 6-digit code; we show only 3 here as a summary. The distribution by year shows that there is no clear evidence of a reporting bias, that COMPUSTAT collects data from more firms in the later years.

A key concern for us is how we could compare inventory across countries. We address this in two ways. First, by following the literature in normalizing inventory by the cost of goods 
sold, we can remove some variation that affects numerator and denominator in the same way. We take this approach in our baseline analyses. Second, in our robustness checks, we marshal detailed information about various conventions our firms take and conduct analyses for subsamples in which firm-years have the same conventions. These conventions are summarized in panels (e) through (h).

In Figure 1, we show our inventory variance for all the firms over time. We see that variance has been increasing in recent years. As mentioned earlier, it is hard to attribute this to COMPUSTAT including more firms in more recent years, since the number of firms actually dropped. We also see that inventory nearer firm boundaries - finished goods and raw materials inventories - are more volatile. We note that the components of inventory are closely correlated: the total variance is higher than the sum of the three, so the covariance terms are not negligible. For example, in 2004, when the variance is 0.046 for aggregate inventory, it is 0.033 for sum of the three -0.010 for raw materials, 0.007 for work in progress, and 0.015 for finished goods. Finally, the global variance is generally larger than within-country variances, as shown in Figure 2.

\section{BASELINE RESULT}

Table 2 shows the baseline results, using VCA. In panel (a), column (1), we report the raw variance components; in column (2), the percentages. The striking result is that country effects explain only $5.8 \%$ of inventory variance. The biggest explanatory factor is firm effects, at $45.9 \%$, and the second, industry effects, at $29.5 \%$. One intuitive way to interpret this is that factors that might have been thought to be country-specific - for example, inadequate access to external financing and therefore, a higher cost of capital - turn out to be really firm-specific (i.e., the 
firm's condition is so adverse that no matter which country it is situated it, it would have faced financial constraints).

In column (3), we report the percentages after taking the square root of the raw components. This last step follows Brush and Bromiley (1997), who suggest that the raw variance components should be scaled non-linearly to properly interpret the components against each other. Specifically, they suggest scaling with square roots. Econometrically, this flattens out the differential explanatory power of the various effects. In our context, this means conservatively attributing more explanatory power to country effects, which we claim is smaller compared with firm and industry effects. In the rest of the paper, all figures reported are after taking square roots.

In panel (b), we show the variance components for various types of inventory. The relatively small size of country effects continues to hold. For finished goods inventory, country effects are much smaller than when we look at inventory in aggregate, at just $6.7 \%$ compared with $12.7 \%$. This would be consistent with several explanations, one of which is that the inventory management technology at the customer interface is considerably more even across countries than that at the supplier interface (for raw materials) or production (for WIP). We do not check this here, but press onto robustness.

\section{ROBUSTNESS ANALYSES}

We undertake a large number robustness analyses. The bottom-line is that they support the baseline results just obtained.

In Figure 3, we show the results of the nested ANOVA for total inventory. Given enormous computational demands, we could run only on fewer observations. We run five random sub- 
samples, all of which give qualitatively similar results (see below). The one reported here uses a sub-sample of 7,341 firm-year observations out of the baseline dataset of 71,203 observations. We also estimate likewise for components of inventory. The results are qualitatively the same and we do not report them here.

In Figure 3, we employ a representation that incrementally imposes zero restrictions on the effects, to account for the fact that the order of entry of these effects into the model can affect the results. Starting from the bottom-most box, where the full model is used, we see that including all three effects - country, industry, firm - explains $88.09 \%$ of inventory variance. This estimation is very significant, with the Wald statistic at 18916.02 and a $p$ value of zero. Going northwest, we impose a restriction on firm effects, and the explained adjusted $R$-squared is reduced to $54.32 \%$. The reduction is not as great if we had gone north. Excluding industry effects, the $R$-squared is $86.52 \%$. In other words, firm effects explain more. If we had gone northeast, the reduction is negligible. Country effects hardly explain anything at this level. All arrows pointing northeast represent zero restrictions on country effects, and we see that the other three northeast arrows reduce $R$-squared by small amounts too $-54.32 \%$ to $53.21 \%$, $86.52 \%$ to $86.52 \%$, and $2.27 \%$ to $0.16 \%$ These incremental reductions compare unfavorably with the reductions for northwest (firm effects) and northward (industry effects) arrows. As mentioned, we run several sub-samples, and the magnitudes of their results are similar. In these sub-samples, for example, the top left northeast arrow for country effects reduce $R$ squared from a range of $2.8 \%$ to $4.8 \%$, to a range of $0.078 \%$ to $0.080 \%$.

In Table 3, we conduct other robustness analyses on our VCA results.

In panel (a), we report two variants of inventory, the dependant variable. In the left half, we 
do not take logs. Although taking log reduces specification error, it can also produce very large negative values for small level values. Chen, et al. (2005) deal with this by winsorizing the data, which we do in our baseline. Indeed, we do all four combinations: with and without $\log$ transformations, and with and without winsorization. In all cases, country effects continue to be the relatively small. In the right half of panel (a), we scale inventory with total assets. The basic finding holds.

In panel (b), we use next-period dependant variable. Recall that our basic result does not claim any causality. The figures with next-period inventory suggest that our result could be stronger: it is consistent with one causality story, in which current-period effects affect nextperiod inventory. It is also consistent with a story that the effects have persistence through time. We do not delve on these possibilities here, but simply want to show that there is evidence stronger than our basic claim.

In panel (c), we show different ways of treating outliers. A number of papers - notably Brush and Bromiley (1997), Hawawini, et al. (2003), Hawawini, et al. (2005), and McNamara, et al. (2005) - point out the sensitivity of VCA to treatments of outliers. The left half of the panel removes the baseline winsorization. The resulting higher error suggests that outliers introduce a fair degree of noise. More important, our main claim that country effects are smaller than firm or industry effects still holds. The right half uses the method introduced into the literature by McNamara, et al. (2005). Following them, we remove firm-years that are outside 3 standard deviations of the industry mean performance. The results hold across the board. The results are robust to the number of standard deviations used, whether 2 or 4 , for example.

In panel (d), we address the concern that our results are might be biased by some systematic 
variation in accounting conventions. We construct sub-samples in which firm-years adopt the same convention and re-estimate our model using these sub-samples. As the panel shows, our finding is robust to these variations. In the right-most column, we combine all different dimensions of conventions - from accounting standards to inventory accounting - to create a sub-sample in which all are the same. Country effects are still the smaller than firm and industry effects, although somewhat larger than before. However, given that we can find only 154 observations in this sub-sample, we are less confident of these larger country effects.

In panel (e), we address the issue of whether our results are robust to time periods. For example, while Aggarwal, et al. (1999)) argue that country-level crises have only local effects, Forbes and Rigobon (2002) argue that countries co-move during periods of downward shocks (which they consider not as contagion, but simply inter-dependence). If the latter is true, the concern is that if our period does not include down periods, then our finding might under-state country effects, which could be bigger during these periods. Fortunately, our period does cover both ups (1994 through 1999) and downs (2000 through 2004). For further robustness, we investigate country effects during these two periods separately. Indeed, our results show that country effects are similar whether in up or down periods, for aggregate and most types of inventories. Importantly, our key message stays: country effects remain the smallest.

In panel (f), we address the issue raised in the literature about sensitivity to firm size (e.g., Bowman \& Helfat (2001)). Larger firms - particularly large business groups - might be able to over-come institutional gaps at the country level (e.g., Khanna and Palepu (2000)). For example, the Charoen Pokphand group in Thailand is in businesses that constitute a supply chain: from chicken feed to chicken rearing to the Kentucky Fried Chicken franchise. In this way, they 
might be able to neutralize country effects, compared with small firms. A counter-view is that while small firms are forced to be operationally efficient everywhere, large firms in some countries - where the focus might be on say, managing politicians - might be operationally less efficient than those with developed capital markets - where information like inventory levels are scrutinized. Both stories could mean country effects might be large when we look at firms of certain sizes. We measure firm size with cost of goods sold, sales, and assets. The results are similar so we report that using cost of goods sold. Panel (f) confirms our basic finding: country effects are small, regardless of firm size.

In panel (g), we consider how much of the effects are persistent over time. The concern is that perhaps much of the industry and firm effects are time-varying, so that country effects might really be big, compared with just the time-stable industry or firm effects. As the results show for aggregate inventory, time-stable industry effects explain $27.0 \%$ of inventory variance while all of country effects - both time-stable (12.0\%) and varying (1.9\%) - are still small by comparison. We do not have the computational resources to disentangle time-varying firm effects (the same applies to all previous research we are aware of; e.g., McGahan and Porter (1999), Brush, et al. (1999)), but we run estimations using small random sub-samples. We show one of these in the second column; the other sub-samples obtain similar results. The rest of the panel show that the finding holds up for specific types of inventory, too.

\section{CONCLUSION}

We have begun by asking whether how significant are country effects in explaining inventory variance among firms. We couch this in the form of a horse-race between the "flat world" and "round earth" hypotheses. We find that, consistent with the "flat world" 
hypothesis, country effects are present, but weaker than firm or industry effects. This is robust to a wide range of sensitivity analyses.

Given our focus on a narrow question, we have not examined many others. As mentioned in the introduction, we have not looked at the direction of causality (although we give a hint of this in our estimation using next-period inventory as dependant variable), nor have we studied the channels through which country, firm, or industry effects affect inventory variance. For example, we have not looked at country effects within sub-samples of countries (e.g., emerging markets) because in our judgment, this is a second order question given that our variable of interest is country effects in the first place.

Our result also suggests that a broader range of operational parameters might be amenable to this same type of investigation. We study inventory here because it is probably the operational parameter most observable and of greatest concern to managers, who "repeatedly describe inventory as wasteful, excessive, indeed 'inherently evil'” (Zipkin (1991), pg. 7). Can the results be generalized to other operational parameters, such as variances in lead time, cash conversion cycle time, etc.? A particularly intriguing one is the suggestion by Netessine and Roumiantsev (2005b), that it is not inventory levels but inventory sensitivity to sales that is a critical operational parameter. What explains inventory sensitivity?

All these fit our investigation into a larger effort in the research community to locate the empirical origins of operations performance. In the near term, the intriguing implication of our finding is that firms might have over-estimated country differences. Subject to further confirmation, our finding suggests that there could be vast scope for operational improvement by learning from firms in other countries. 


\section{REFERENCES}

Aggarwal, R., C. Inclan and R. P. C. Leal. "Volatility in Emerging Stock Markets," Journal of Financial and Quantitative Analysis 34(1999), 33-55.

Alles, M., A. Amershi, S. Datar and R. Sarkar. "Information and Incentive Effects of Inventory in Jit Production," Management Science 46(2000), 1528-1544.

Amit, R. and P. J. H. Schoemaker. "Strategic Assets and Organizational Rent," Strategic Management Journal 14(1993), 33-46.

Balakrishnan, R., T. J. Linsmeier and M. Venkatachalam. "Financial Benefits from Jit Adoption: Effects of Customer Concentration and Cost Structure," Accounting Review 71(1996), 183-205.

Barney, J. B. "Strategic Factor Markets: Expectations, Luck, and Business Strategy," Management Science 32(1986), 1231-1241.

Basu, S. and D. N. Weil. "Appropriate Technology and Growth," Quarterly Journal of Economics 113(1998), 1025-1054.

Bernard, A. and C. I. Jones. "Comparing Apples to Oranges: Productivity Convergence and Measurement across Industries and Countries," American Economic Review 86(1996), 12161238.

Blinder, A. S. "Retail Inventory Behavior and Business Fluctuations," Brookings Papers on Economic Activity 2(1981), 443-520.

Bowman, E. H. and C. E. Helfat. "Does Corporate Strategy Matter?," Strategic Management Journal 22(2001), 1-23.

Brush, T. H. and P. Bromiley. "What Does a Small Corporate Effect Mean? A Variance Components Simulation of Corporate and Business Effects," Strategic Management Journal 18(1997), 825-835.

Brush, T. H., P. Bromiley and M. Hendrickx. "The Relative Influence of Industry and Corporation on Business Segment Performance: An Alternative Estimate," Strategic Management Journal 20(1999), 519-547.

Caves, R. E. "Multinational Firms, Competition, and Productivity in Host-Country Markets," Economica 41(1974), 176-193.

---. Industrial Efficiency in Six Nations: Introduction and Summary. Cambridge and London, 1992

Chen, H., M. Z. Frank and O. Q. Wu. "What Actually Happened to the Inventories of American Companies between 1981 and 2000?," Management Science 51(2005), 1015-1031.

Chikan, A. and D. C. Whybark. "Cross-National Comparison of Production Inventory Management-Practices," Engineering Costs and Production Economics 19(1990), 149-156.

Demsetz, H. "Industry Structure, Market Rivalry, and Public Policy," Journal of Law and Economics 16(1973), 1-10.

Dierickx, I. and K. Cool. "Asset Stock Accumulation and Sustainability of Competitive Advantage," Management Science 35(1989), 1504-1511.

Fisher, M. and C. D. Ittner. "The Impact of Product Variety on Automobile Assembly Operations: Empirical Evidence and Simulation Analysis," Management Science 45(1999), 771786.

Fisher, M. L. What Is the Right Supply Chain for Your Product?, Harvard Business Review, 1997

Forbes, K. J. and R. Rigobon. "No Contagion, Only Interdependence: Measuring Stock Market 
Comovements," Journal of Finance 57(2002), 2223-2261.

Friedman, T. L. The World Is Flat. New York, NY, Farrar, Straus and Girous, 2005

Gaur, V., M. Fisher and A. Raman. "An Econometric Analysis of Inventory Turnover

Performance in Retail Services," Management Science 51(2005), 181-194.

Gompers, P., J. Lerner and D. Scharfstein. "Entrepreneurial Spawning: Public Corporations and the Genesis of New Ventures, 1986-1999," Journal of Finance (2005).

Goodfriend, M. and J. McDermott. "Industrial Development and the Convergence Question," American Economic Review 88(1998), 1277-1289.

Hawawini, G., V. Subramanian and P. Verdin. "Is Performance Driven by Industry- or FirmSpecific Factors? A New Look at the Evidence," Strategic Management Journal 24(2003), 1-16.

---. "Is Performance Driven by Industry- or Firm-Specific Factors? A Reply to Mcnamara, Aime, and Vaaler," Strategic Management Journal 26(2005), 1083-1086.

Hendricks, K. B. and V. R. Singhal. "Does Implementing an Effective Tqm Program Actually Improve Operating Performance? Empirical Evidence from Firms That Have Won Quality Awards," Management Science 43(1997), 1258-1274.

---. "Association between Supply Chain Glitches and Operating Performance," Management Science 51(2005), 695?611.

Hopp, W. J., M. L. Spearman and R. Q. Zhang. "Easily Implementable Inventory Control Policies," Operations Research 45(1997), 327-340.

Iyer, A. V. and M. E. Bergen. "Quick Response in Manufacturer-Retailer Channels," Management Science 43(1997), 559-570.

Jaikumar, R. Massimo Menichetti, Harvard Business School Case: 14. Boston, MA: Harvard Business School, 1985

Jorgenson, D. "Productivity and Economic-Growth in Japan and the United-States " American Economic Review 78(1988), 217-222.

Jovanovic, B. "Selection and the Evolution of Industry," Econometrica 50(1982), 649-670.

Kapuscinski, R., R. Q. Zhang, P. Carbonneau, R. L. Moore and B. Reeves. "Inventory Decisions in Dell's Supply Chain," Interfaces 34(2004), 191-205.

Khanna, T. and K. Palepu. "Is Group Affiliation Profitable in Emerging Markets? An Analysis of Diversified Indian Business Groups," Journal of Finance 55(2000), 867-891.

Khanna, T. and J. W. Rivkin. The Structure of Profitability around the World, Harvard Business School Working Paper 01-056. Boston MA: Harvard Business School, 2001

Krugman, P. and A. J. Venables. "Globalization and the Inequality of Nations," Quarterly Journal of Economics 110(1995), 857-880.

La Porta, R., F. Lopez-de-Silanes, A. Shleifer and R. W. Vishny. "Law and Finance," Journal of Political Economy 106(1998), 1113-1155.

Lai, R. Inventory Heterogeneity, Harvard NOM Working Paper No. 06-09. Boston, MA: Harvard Business School, 2006a

---. Manufacturing Inventory around the World. Paper presented at the MSOM, Atlanta, GA, 2006b.

Lieberman, M. B. and L. Demeester. "Inventory Reduction and Productivity Growth: Linkages in the Japanese Automotive Industry," Management Science 45(1999), 466-485.

Lieberman, M. B., S. Helper and L. Demeester. "The Empirical Determinants of Inventory Levels in High-Volume Manufacturing," Production and Operations Management 8(1999), 44-55. 
Makino, S., T. Isobe and C. M. Chan. "Does Country Matter?," Strategic Management Journal 25(2004), 1027-1043.

McCarthy, J. and E. Zakrajsek. Inventory Dynamics and Business Cycles: What Has Changed? New York: Federal Reserve Bank of New York, 2002

McGahan, A. M. and M. E. Porter. "How Much Does Industry Matter, Really?," Strategic Management Journal 18(1997), 15-30.

---. "The Persistence of Shocks to Profitability," Review of Economics and Statistics 81(1999), 143153.

McGahan, A. M. and M. Porter. "What Do We Know About Variance in Accounting Profitability?," Management Science 48(2002), 834-851.

McGahan, A. M. and M. E. Porter. "Comment on 'Industry, Corporate and Business-Segment Effects and Business Performance: A Non-Parametric Approach' by Ruefli and Wiggins," Strategic Management Journal 26(2005), 873-880.

McNamara, G., F. Aime and P. Vaaler. "Is Performance Driven by Industry-or Firm-Specific Factors? A Response to Hawawini, Subramanian, and Verdin," Strategic Management Journal 26(2005), 1075-1081.

Netessine, S. and S. Roumiantsev. Empirical Testing of Classical Inventory Management Models: Evidence from Us Public Companies. Paper presented at the POMS Conference, Chicago, 2005a.

---. Should Inventory Policy Be Lean or Responsive: Evidence for Us Public Companies, Wharton School Working Paper. Philadelphia, PA: Wharton School, 2005b

North, D. C. Institutions, Institutional Change and Economic Performance. Cambridge, Cambridge University Press, 1990

Porter, M. E. Competitive Strategy: Techniques for Analyzing Industries and Competitors. New York, Free Press, 1980

Prasad, S. and S. Babbar. "International Operations Management Research," Journal Of Operations Management 18(2000), 209-247.

Prasad, S., S. Babbar and J. Motwani. "International Operations Strategy: Current Efforts and Future Directions," International Journal of Operations \& Production Management 21(2001), 645665.

Raman, A., M. L. Fisher, J. Hammond and W. Obermeyer. "Configuring a Supply Chain to Reduce the Cost of Demand Uncertainty," Production and Operations Management Journal 6(1997), 211-225.

Roquebert, J. A., R. L. Phillips and P. A. Westfall. "Markets Vs. Management: What 'Drives' Profitability?," Strategic Management Journal 17(1996), 653-664.

Rumelt, R. P., "Towards a Strategic Theory of the Firm," in Lamb, R. B. (Ed.), Competitive Strategic Management. Englewood Cliffs, N.J.: Prentice-Hall, 1984

---. "How Much Does Industry Matter?," Strategic Management Journal 12(1991), 167-185.

Sakakibara, S., B. B. Flynn, R. G. Schroeder and W. T. Morris. "The Impact of Just-in-Time Manufacturing and Its Infrastructure on Manufacturing Performance," Management Science 43(1997), 1246-1257.

Schmalensee, R. "Do Markets Differ Much?," American Economic Review 75(1985), 341-351.

Schultz, K., D. C. Juran and J. W. Boudreau. "The Effects of Low Inventory on the Development of Productivity Norms," Management Science 45(1999), 1664-1678. 
Searle, S. R., G. Casella and C. E. McColluch. Variance Components. New York, NY, Wiley, 1992

Wernerfelt, B. "A Resource-Based View of the Firm," Strategic Management Journal 5(1984), 171180.

Zeira, J. "Workers, Machines, and Economic Growth," Quarterly Journal of Economics 113(1998), 1091-1117.

Zipkin, P. H. Does Manufacturing Need a Jit Revolution?, Harvard Business Review: 5-11, 1991 


\section{Table 1 - Summary Statistics}

The dataset includes all 71,203 annual firm-year observations in the COMPUSTAT tapes, for years 1994 through 2004 and for the manufacturing industry (NAICS codes 31 through 33). Each observation is a firm year, with 9,617 unique firms from 70 countries. For firms that restate their numbers, we use the restated figures. Inventory figures are all scaled with the costs of goods sold. To deal with outliers, we winsorize the data at $1 \%$ and $99 \%$.

$$
\text { (a) - Inventory }
$$

Inventory figures are all scaled by contemporaneous costs of goods sold, in local currencies for both numerators and denominators.

\begin{tabular}{lccc}
\hline & $N$ & Median & Std. dev. \\
\cline { 2 - 4 } Year & 71203 & 1,999 & 2.94 \\
Inventory - total & 51187 & 0.22 & 0.21 \\
Inventory - raw materials & 34965 & 0.08 & 0.11 \\
Inventory - WIP (work in progress) & 34066 & 0.03 & 0.09 \\
Inventory - finished goods & 34785 & 0.09 & 0.12 \\
\hline
\end{tabular}

(b) - Distribution by Year

\begin{tabular}{lcc}
\hline & Freq. & Percent \\
\cline { 2 - 3 } 1994 & 4,518 & 6.35 \\
1995 & 4,829 & 6.78 \\
1996 & 5,755 & 8.08 \\
1997 & 7,362 & 10.34 \\
1998 & 7,609 & 10.69 \\
1999 & 7,633 & 10.72 \\
2000 & 7,478 & 10.5 \\
2001 & 7,083 & 9.95 \\
2002 & 6,886 & 9.67 \\
2003 & 6,655 & 9.35 \\
2004 & 5,395 & 7.58 \\
Total & 71,203 & 100 \\
\hline
\end{tabular}


(c) - Distribution by Country

\begin{tabular}{|c|c|c|c|c|c|c|}
\hline 1 & Argentina & 145 & 25 Hong Kong, China & 458 & 49 Papua New Guinea & 7 \\
\hline 2 & Australia & 921 & 26 Hungary & 92 & 50 Peru & 82 \\
\hline 3 & Austria & 489 & 27 Iceland & 10 & 51 Philippines & 374 \\
\hline 4 & Bangladesh & 10 & 28 India & 1,728 & 52 Poland & 143 \\
\hline 5 & Belgium & 509 & 29 Indonesia & 1,188 & 53 Portugal & 202 \\
\hline 6 & Bermuda & 1,659 & 30 Ireland & 185 & 54 Romania & 15 \\
\hline 7 & Brazil & 804 & 31 Israel & 272 & 55 Russian Federation & 20 \\
\hline 8 & British Virgin Islands & 16 & 32 Italy & 1,036 & 56 Singapore & 1,430 \\
\hline 9 & Canada & 2,083 & 33 Japan & 14,629 & 57 Slovak Republic & 25 \\
\hline 10 & Cayman Islands & 478 & 34 Jordan & 8 & 58 Slovenia & 25 \\
\hline 11 & Chile & 332 & 35 Korea, Rep. & 1,014 & 59 South Africa & 273 \\
\hline 12 & China & 587 & 36 Lithuania & 2 & 60 Spain & 610 \\
\hline 13 & Colombia & 129 & 37 Luxembourg & 44 & 61 Sri Lanka & 4 \\
\hline 14 & Croatia & 16 & 38 Malaysia & 3,089 & 62 Sweden & 1,058 \\
\hline 15 & Cyprus & 7 & 39 Mauritius & 7 & 63 Switzerland & 1,039 \\
\hline 16 & Czech Republic & 60 & 40 Mexico & 347 & 64 Taiwan & 1,416 \\
\hline 17 & Denmark & 735 & 41 Morocco & 28 & 65 Thailand & 1,625 \\
\hline 18 & Egypt, Arab Rep. & 35 & 42 Namibia & 3 & 66 Turkey & 252 \\
\hline 19 & Estonia & 9 & 43 Netherlands & 833 & 67 United Kingdom & 4,109 \\
\hline 20 & Finland & 595 & 44 Netherlands Antilles & 10 & 68 United States & 16,921 \\
\hline 21 & France & 2,655 & 45 New Zealand & 156 & 69 Venezuela, RB & 53 \\
\hline 22 & Germany & 3,135 & 46 Norway & 443 & 70 Zimbabwe & 13 \\
\hline 23 & Greece & 272 & 47 Pakistan & 214 & & \\
\hline 24 & Guyana & 10 & 48 Panama & 20 & Total & 71,203 \\
\hline
\end{tabular}

(d) - Distribution by Industry

In this summary, industries are grouped by 3-digit codes. The dataset uses full 6-digit NAICS codes.

\begin{tabular}{llll}
\hline NAICS & & & \\
\hline 311 & Food Manufacturing & Percent & Cum. \\
312 & Beverage and Tobacco Product Manufacturing & 5,024 & 7.06 \\
313 & Textile Mills & 2,206 & 3.1 \\
314 & Textile Product Mills & 1,857 & 2.61 \\
315 & Apparel Manufacturing & 409 & 0.57 \\
316 & Leather and Allied Product Manufacturing & 1,873 & 2.63 \\
321 & Wood Product Manufacturing & 666 & 0.94 \\
322 & Paper Manufacturing & 988 & 1.39 \\
323 & Printing and Related Support Activities & 2,456 & 3.45 \\
324 & Petroleum and Coal Products Manufacturing & 781 & 1.1 \\
325 & Chemical Manufacturing & 1,078 & 1.51 \\
326 & Plastics and Rubber Products Manufacturing & 9,996 & 14.04 \\
327 & Nonmetallic Mineral Product Manufacturing & 2,271 & 3.19 \\
331 & Primary Metal Manufacturing & 3,478 & 4.88 \\
332 & Fabricated Metal Product Manufacturing & 3,921 & 5.51 \\
333 & Machinery Manufacturing & 2,920 & 4.1 \\
334 & Computer and Electronic Product Manufacturing & 7,083 & 9.95 \\
335 & Electrical Equipment, Appliance, and Component Manufacturing & 12,301 & 17.28 \\
336 & Transportation Equipment Manufacturing & 3,555 & 4.99 \\
337 & Furniture and Related Product Manufacturing & 4,494 & 6.31 \\
339 & Miscellaneous Manufacturing & 1,063 & 1.49 \\
$31-33$ & Unclassified Manufacturing & 2,763 & 3.88 \\
& Total & 20 & 0.03 \\
\hline
\end{tabular}


(e) - Distribution by Accounting Standard

Domestic standards generally in accordance with IASC (International Accounting Standards Committee) and OECD (Org for Ec Cooperation \& Development) guidelines Domestic standards generally in accordance with IASC guidelines Domestic standards generally in accordance with OECD guidelines Accounts reclassified to show allowance for doubtful accounts and/or accumulated depreciation as a reduction of assets rather than liabilities

Domestic standards

\begin{tabular}{cc} 
Freq. & Percent \\
\hline 18 & 0.03 \\
2,785 & 3.91 \\
51 & 0.07 \\
2 & 0 \\
& \\
67,307 & 94.53 \\
62 & 0.09 \\
& \\
339 & 0.48 \\
232 & 0.33 \\
& \\
407 & 0.57 \\
\hline 71,203 & 100 \\
\hline
\end{tabular}

(f) - Distribution by Accounting Method

\section{Current Cost}

Historic Cost (company does not revalue fixed assets)

Modified Historic Cost (company states assets at cost in its statements but assumes replacement cost for depreciation)

Total and generally in accordance with IASC and OECD guidelines into English)

United States' standards

Total

\begin{tabular}{cc} 
Freq. & Percent \\
\hline 22 & 0.03 \\
50,639 & 71.16 \\
20,500 & 28.81 \\
& \\
\hline 71,161 & 100 \\
\hline
\end{tabular}

(g) - Distribution by Consolidation Method

Only domestic subsidiaries are consolidated

\begin{tabular}{cc} 
Freq. & Percent \\
\hline 1 & 0 \\
66,272 & 93.07 \\
26 & 0.04 \\
4,904 & 6.89 \\
\hline 71,203 & 100
\end{tabular}

(h) - Distribution by Inventory Accounting Method

No Inventory

First In, First Out (FIFO)

Last In, First Out (LIFO)

Specific Identification

Average Cost

Retail Method (See note below)

Standard Cost

Current or Replacement Cost

Primarily First In, First Out (FIFO)

Primarily Last In, First Out (LIFO)

Primarily Specific Identification

Primarily Average Cost

Primarily Retail Method (See note below)

Primarily Standard Cost

Primarily Current or Replacement Cost Grand Total

\begin{tabular}{rr} 
Freq. & Percent \\
\hline 168 & 0.34 \\
17,240 & 35.29 \\
1,572 & 3.22 \\
139 & 0.28 \\
13,692 & 28.03 \\
21 & 0.04 \\
771 & 1.58 \\
503 & 1.03 \\
5,269 & 10.79 \\
3,166 & 6.48 \\
934 & 1.91 \\
1,875 & 3.84 \\
3 & 0.01 \\
3,431 & 7.02 \\
70 & 0.14 \\
\hline 48,854 & 100.00 \\
\hline &
\end{tabular}




\section{Table 2 - Baseline Variance Decomposition Using VCA}

The dataset includes all 71,203 annual firm-year observations in the COMPUSTAT tapes, for years 1994 through 2004 and for the manufacturing industry (NAICS codes 31 through 33). Each observation is a firm year, with 9,617 unique firms from 70 countries. For firms that restate their numbers, we use the restated figures. Inventory figures are all scaled with the costs of goods sold. To deal with outliers, we winsorize the data at $1 \%$ and $99 \%$.

$$
\text { (a) - Total Inventory }
$$

$N=50868$. In column (3), "Square roots" takes the square root of the raw variance components before computing the percentages, as in Brush and Bromiley (1997).

\begin{tabular}{lccc}
\hline & $(1)$ & $(2)$ & $(3)$ \\
& Raw & Percentages & Square roots \\
\cline { 2 - 4 } Year & 0.000096 & $0.0 \%$ & $0.7 \%$ \\
Country & $\mathbf{0 . 0 3}$ & $\mathbf{5 . 8 \%}$ & $\mathbf{1 2 . 7 \%}$ \\
Industry & 0.149 & $29.5 \%$ & $28.5 \%$ \\
Firm & 0.232 & $45.9 \%$ & $35.5 \%$ \\
Error & 0.095 & $18.7 \%$ & $22.7 \%$ \\
\hline
\end{tabular}

(b) - Components of Inventory

WIP is "work in progress." All percentages have been transformed using square root.

\begin{tabular}{lccc}
\hline & $(1)$ & $(2)$ & $(3)$ \\
Year & Raw materials & WIP & Finished goods \\
\cline { 2 - 4 } Country & $1.1 \%$ & $4.9 \%$ & $1.6 \%$ \\
Industry & $12.2 \%$ & $13.4 \%$ & $6.7 \%$ \\
Firm & $20.2 \%$ & $25.7 \%$ & $24.3 \%$ \\
Error & $38.4 \%$ & $33.3 \%$ & $39.5 \%$ \\
$N$ & $28.1 \%$ & $22.8 \%$ & $27.8 \%$ \\
\hline
\end{tabular}




\section{Table 3 - Robustness Analyses}

The dataset includes all 71,203 annual firm-year observations in the COMPUSTAT tapes, for years 1994 through 2004 and for the manufacturing industry (NAICS codes 31 through 33). Each observation is a firm year, with 9,617 unique firms from 70 countries. For firms that restate their numbers, we use the restated figures. Inventory figures are all scaled with the costs of goods sold. All but panel (b) have data winsorized at $1 \%$ and $99 \%$.

$$
\text { (a) - Variants of Dependent Variables }
$$

The left half uses inventory scaled by cost of goods sold, but without taking logs as in the baseline. The right half uses inventory scaled by total assets.

\begin{tabular}{|c|c|c|c|c|c|c|c|c|}
\hline & Levels & & & & Scaled by & assets & & \\
\hline & Total & Raw mat & $\overline{\mathrm{WIP}}$ & Fin gds & Total & Raw mat & WIP & Fin gds \\
\hline Year & $0.6 \%$ & $1.6 \%$ & $1.9 \%$ & $1.0 \%$ & $5.1 \%$ & $3.6 \%$ & $6.0 \%$ & $3.9 \%$ \\
\hline Country & $10.8 \%$ & $9.2 \%$ & $9.8 \%$ & $4.2 \%$ & $9.8 \%$ & $9.4 \%$ & $13.4 \%$ & $8.7 \%$ \\
\hline Industry & $27.3 \%$ & $18.8 \%$ & $27.2 \%$ & $25.5 \%$ & $22.5 \%$ & $21.7 \%$ & $18.7 \%$ & $22.6 \%$ \\
\hline Firm & $33.6 \%$ & $38.7 \%$ & $37.0 \%$ & $38.6 \%$ & $38.0 \%$ & $37.7 \%$ & $37.5 \%$ & $39.4 \%$ \\
\hline Error & $27.7 \%$ & $31.6 \%$ & $24.1 \%$ & $30.7 \%$ & $24.7 \%$ & $27.7 \%$ & $24.4 \%$ & $25.5 \%$ \\
\hline $\mathrm{N}$ & 51187 & 34965 & 34066 & 34785 & 69571 & 50167 & 43512 & 49444 \\
\hline
\end{tabular}

(b) - Next-Period Dependant Variables

\begin{tabular}{lcccl}
\hline Year & Total & Raw mat & WIP & Fin gds \\
\cline { 2 - 3 } Country & $1.3 \%$ & $1.6 \%$ & $4.9 \%$ & $1.9 \%$ \\
Industry & $29.0 \%$ & $10.8 \%$ & $13.5 \%$ & $\mathbf{6 . 6 \%}$ \\
Firm & $35.5 \%$ & $39.0 \%$ & $26.4 \%$ & $24.4 \%$ \\
Error & $22.2 \%$ & $27.5 \%$ & $33.2 \%$ & $39.8 \%$ \\
$\mathrm{~N}$ & 44300 & $22.1 \%$ & $27.2 \%$ \\
\hline
\end{tabular}

(c) - Outlier Treatment

The "McNamara" method removes firm-years that are outside 3 standard deviations of the industry mean performance - see McNamara, et al. (2005).

\begin{tabular}{|c|c|c|c|c|c|c|c|c|}
\hline & \multicolumn{4}{|l|}{ None } & \multicolumn{4}{|l|}{ McNamara } \\
\hline & Total & Raw mat & WIP & Fin gds & Total & Raw mat & WIP & Fin gds \\
\hline Year & $0.7 \%$ & $1.0 \%$ & $4.8 \%$ & $1.5 \%$ & $0.7 \%$ & $1.0 \%$ & $4.8 \%$ & $1.5 \%$ \\
\hline $\begin{array}{l}\text { Country } \\
\text { Industry }\end{array}$ & $\begin{array}{l}12.3 \% \\
27.1 \%\end{array}$ & $\begin{array}{l}11.9 \% \\
196 \%\end{array}$ & $\begin{array}{l}13.1 \% \\
25.1 \%\end{array}$ & $\begin{array}{c}\mathbf{6 . 6 \%} \\
23.6 \%\end{array}$ & $\begin{array}{l}12.3 \% \\
27.1 \%\end{array}$ & $\begin{array}{l}11.9 \% \\
196 \%\end{array}$ & $\begin{array}{l}13.1 \% \\
25.1 \%\end{array}$ & $\begin{array}{r}\mathbf{6 . 6 \%} \\
23.6 \%\end{array}$ \\
\hline Firm & $34.4 \%$ & $37.4 \%$ & $33.5 \%$ & $38.6 \%$ & $34.4 \%$ & $37.4 \%$ & $33.5 \%$ & $38.6 \%$ \\
\hline Error & $25.5 \%$ & $30.1 \%$ & $23.6 \%$ & $29.7 \%$ & $25.5 \%$ & $30.1 \%$ & $23.6 \%$ & $29.7 \%$ \\
\hline$N$ & 50868 & 33709 & 29218 & 33202 & 50868 & 33709 & 29218 & 33202 \\
\hline
\end{tabular}


(d) - Sub-samples by Accounting Convention

Sub-sample (1) uses only observations that adopt "Domestic standards generally in accordance with IASC guidelines" and (2), "Domestic standards in accordance with principles generally accepted in the United States." Sub-sample (3) uses only observations adopting "Historic Cost" and (4), "Modified Historic Cost (company states assets at cost in its statements but assumes replacement cost for depreciation)". Sub-sample (5) uses observations adopting "Fully consolidated (parent companies and subsidiaries)" and (6), "Nonconsolidated (parent company only)." Sub-sample (7) uses observations adopting "First In, First Out (FIFO)" and (8), "Average Cost." Sub-sample (9) uses observations at the intersection of those in (1), (3), (5), and (7).

\begin{tabular}{|c|c|c|c|c|c|c|c|c|c|}
\hline & $\begin{array}{l}\text { cct. } \\
\text { andards }\end{array}$ & & $\begin{array}{l}\text { Acct. } \\
\text { methods }\end{array}$ & & $\begin{array}{l}\text { Consol. } \\
\text { method }\end{array}$ & & $\begin{array}{l}\text { Inventory } \\
\text { accounting }\end{array}$ & & Combinec \\
\hline & & (2) & $(3)$ & $(4)$ & (5) & (6) & $(7)$ & (8) & (9) \\
\hline Yea & $7.4 \%$ & $4.7 \%$ & $0.3 \%$ & $3.4 \%$ & $1.4 \%$ & $2.7 \%$ & $3.7 \%$ & $4.2 \%$ & $5.7 \%$ \\
\hline ountry & $9.6 \%$ & $13.8 \%$ & $13.3 \%$ & 11. & $11.7 \%$ & 17 & $7.0 \%$ & $9.4 \%$ & $21.7 \%$ \\
\hline Industry & $43.4 \%$ & $24.8 \%$ & $30.1 \%$ & $22.1 \%$ & $28.5 \%$ & $29.2 \%$ & $26.0 \%$ & $22.6 \%$ & $38.9 \%$ \\
\hline Firm & $18.9 \%$ & $36.8 \%$ & $34.6 \%$ & $37.9 \%$ & $35.8 \%$ & $32.7 \%$ & $37.1 \%$ & $36.3 \%$ & $28.6 \%$ \\
\hline Error & $20.7 \%$ & $19.9 \%$ & $21.7 \%$ & $24.8 \%$ & $22.6 \%$ & $18.4 \%$ & $26.2 \%$ & $27.4 \%$ & $5.0 \%$ \\
\hline$N$ & 1390 & 287 & 38830 & 12003 & 47810 & 3048 & 12545 & 7975 & 154 \\
\hline
\end{tabular}

(e) - Time Periods

\begin{tabular}{|c|c|c|c|c|c|c|c|c|}
\hline & \multicolumn{4}{|l|}{$94-99$} & \multicolumn{4}{|l|}{$00-04$} \\
\hline & Total & Raw mat & WIP & Fin gds & Total & Raw mat & WIP & Fin gds \\
\hline Year & $1.1 \%$ & $0.7 \%$ & $2.8 \%$ & $0.2 \%$ & $1.7 \%$ & $2.2 \%$ & $1.9 \%$ & $1.2 \%$ \\
\hline Country & $13.5 \%$ & $16.8 \%$ & $13.0 \%$ & $5.2 \%$ & $11.8 \%$ & $8.4 \%$ & $12.8 \%$ & $8.7 \%$ \\
\hline Industry & $29.4 \%$ & $20.5 \%$ & $26.1 \%$ & $26.2 \%$ & $27.9 \%$ & $20.0 \%$ & $27.8 \%$ & $23.7 \%$ \\
\hline Firm & $36.1 \%$ & $38.4 \%$ & $36.0 \%$ & $43.3 \%$ & $37.4 \%$ & $42.9 \%$ & $36.5 \%$ & $41.0 \%$ \\
\hline Error & $19.8 \%$ & $23.5 \%$ & $22.0 \%$ & $25.1 \%$ & $21.2 \%$ & $26.5 \%$ & $21.0 \%$ & $25.3 \%$ \\
\hline$N$ & 25579 & 16938 & 14545 & 16530 & 25289 & 16771 & 14673 & 16672 \\
\hline
\end{tabular}

(f) - Firm Size

Firm size is measured using cost of goods sold. The dataset has been divided into four quartiles.

\begin{tabular}{|c|c|c|c|c|}
\hline & 1 (smallest) & 2 & 3 & 4 (largest) \\
\hline Year & $1.2 \%$ & $1.9 \%$ & $2.5 \%$ & $1.1 \%$ \\
\hline Country & $8.4 \%$ & $4.6 \%$ & $10.3 \%$ & $13.9 \%$ \\
\hline Industry & $21.5 \%$ & $28.3 \%$ & $30.1 \%$ & $34.2 \%$ \\
\hline Firm & $39.6 \%$ & $40.7 \%$ & $35.8 \%$ & $34.6 \%$ \\
\hline Error & $29.3 \%$ & $24.4 \%$ & $21.3 \%$ & $16.2 \%$ \\
\hline
\end{tabular}

(g) - Interactions and Persistence

The "Total (sub-sample)" column uses a randomly selected sub-sample, for computational reasons.

\begin{tabular}{|c|c|c|c|c|c|}
\hline & Total & $\begin{array}{l}\text { Total } \\
\text { (sub-sample) }\end{array}$ & Raw mat & WIP & Fin gds \\
\hline Year & $0.6 \%$ & $1.9 \%$ & $2.0 \%$ & $4.7 \%$ & $1.4 \%$ \\
\hline Country & $12.0 \%$ & $3.0 \%$ & $11.1 \%$ & $12.8 \%$ & $6.5 \%$ \\
\hline Country $\times$ Year & $1.9 \%$ & $1.2 \%$ & $5.4 \%$ & $1.8 \%$ & $1.6 \%$ \\
\hline Industry & $27.0 \%$ & $34.8 \%$ & $18.4 \%$ & $24.6 \%$ & $23.7 \%$ \\
\hline Industry $\times$ Year & $3.8 \%$ & $1.0 \%$ & $3.0 \%$ & $2.5 \%$ & $1.3 \%$ \\
\hline Firm & $33.7 \%$ & $21.8 \%$ & $35.1 \%$ & $31.9 \%$ & $38.5 \%$ \\
\hline Firm $\times$ Year & & $15.9 \%$ & & & \\
\hline Error & $21.1 \%$ & $20.3 \%$ & $25.1 \%$ & $21.7 \%$ & $27.0 \%$ \\
\hline$N$ & 50868 & 7341 & 33709 & 29218 & 33202 \\
\hline
\end{tabular}




\section{Figure 1 - Variance Over Time}

The dataset includes all 71,203 annual firm-year observations in the COMPUSTAT tapes, for years 1994 through 2004 and for the manufacturing industry (NAICS codes 31 through 33). Each observation is a firm year, with 9,617 unique firms from 70 countries. For firms that restate their numbers, we use the restated figures. Inventory figures are all scaled with the costs of goods sold. To deal with outliers, we winsorize the data at $1 \%$ and $99 \%$.

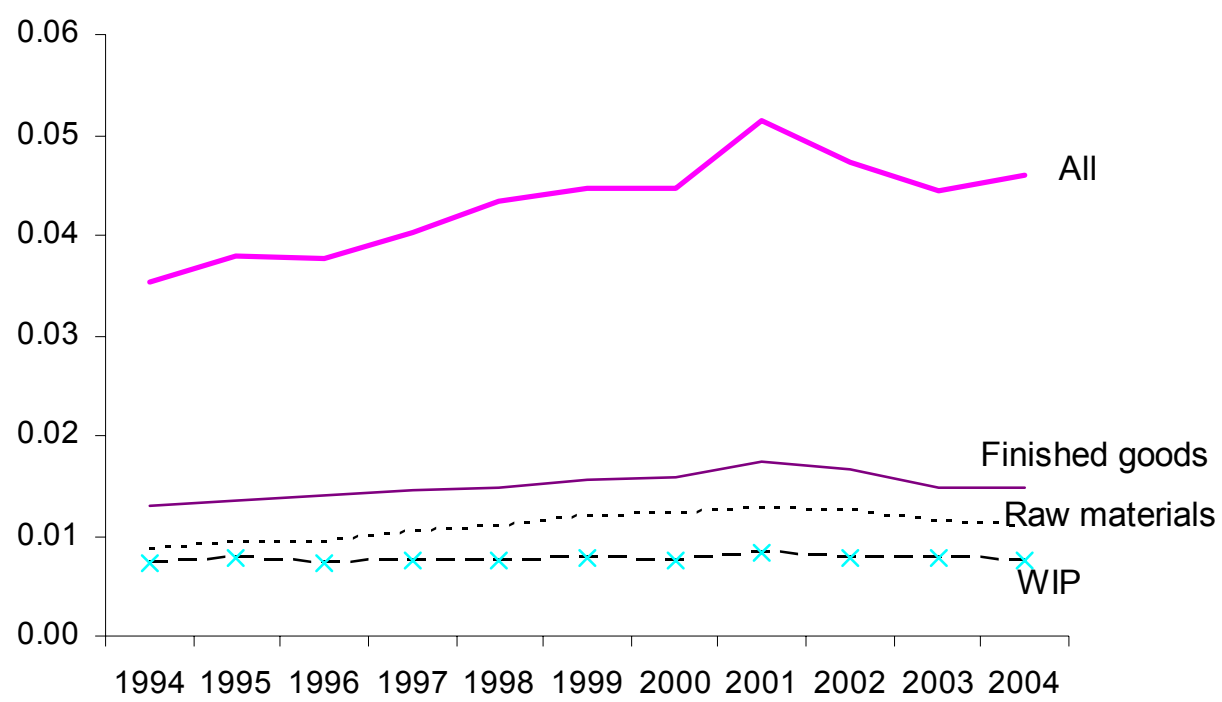




\section{Figure 2 - Variance by Country}

The values shown are for firm-year observations of inventory, pooled over all firms for the period. The dataset includes all 71,203 annual firm-year observations in the COMPUSTAT tapes, for years 1994 through 2004 and for the manufacturing industry (NAICS codes 31 through 33). Each observation is a firm year, with 9,617 unique firms from 70 countries. In this summary, we show only countries with at least 200 observations. For firms that restate their numbers, we use the restated figures. Inventory figures are all scaled with the costs of goods sold. To deal with outliers, we winsorize the data at $1 \%$ and $99 \%$.

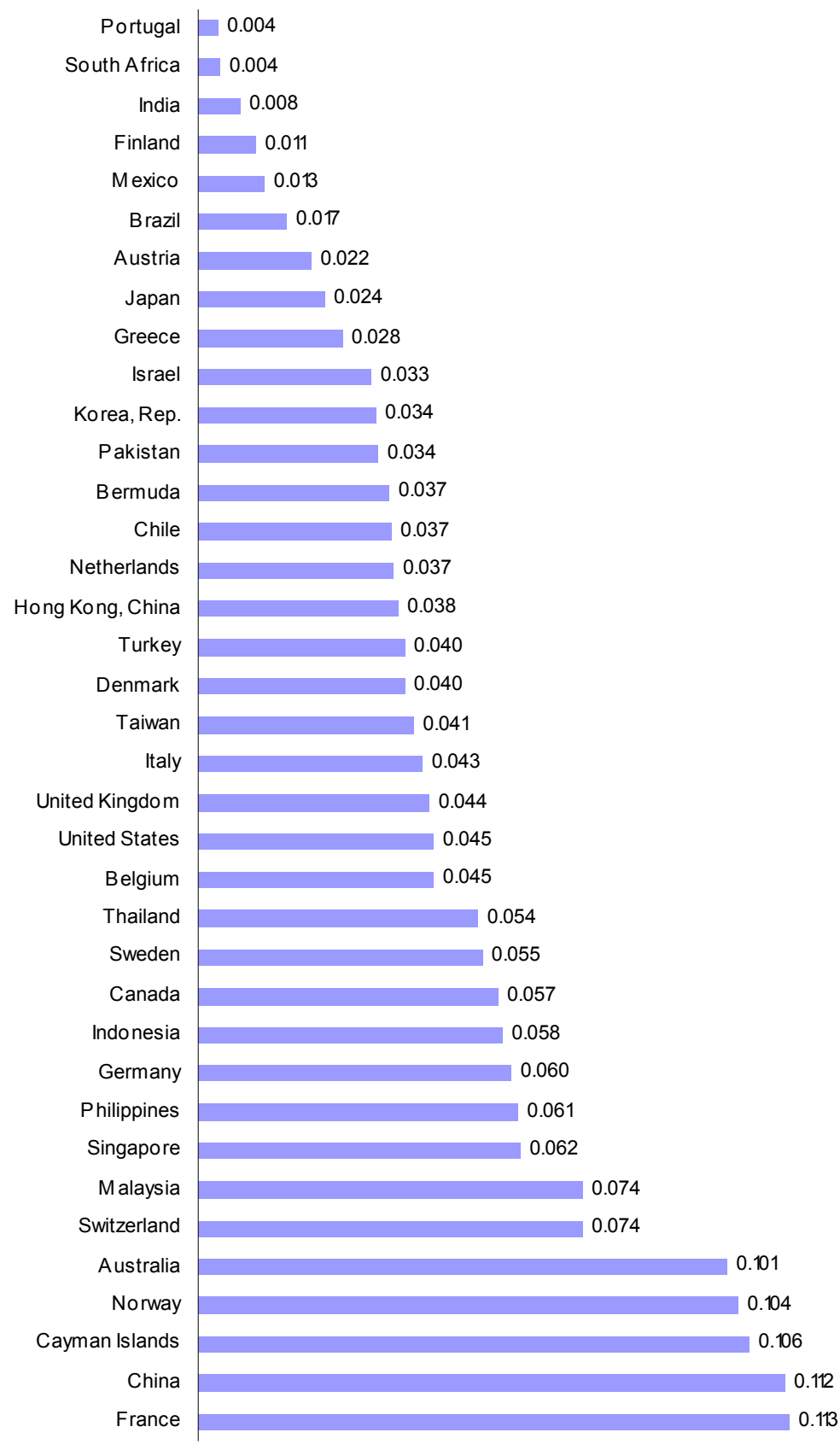




\section{Figure 3 - Nested ANOVA of Total Inventory}

The specification uses just the primary business model and industry for each firm-year:

$$
i_{c, n, f, t}=\mu_{\ldots .}+\alpha_{c}+\beta_{n}+\gamma_{f}+\delta_{t}+\varepsilon_{c, n, f, t}
$$

where $i_{c, n, f, t}$ is inventory (scaled by cost of goods sold of firm $f$ s inventory over year $t$ when it has primary industry $n$ at the NAICS 6-digit level and is located in country $c ; \mu . \ldots$ is a constant for the overall mean effect with the three dots denoting averaging over the three indices, $\alpha_{c}$ the country effect, $\beta_{n}$ the (primary) industry effect, $\gamma_{f}$ the firm effect, $\delta_{t}$ the year effect, and $\varepsilon_{c, n, f, t}$ is white. The estimation is run with $\operatorname{AR}(1)$ disturbances.

Starting from the bottom is the unrestricted model. Arrows pointing northwest represent restrictions on firm effects, those pointing north represent restrictions on industry, and those northeast represent restrictions on country. The figures on the arrows are $p$-values of the restrictions. The figures in the boxes are the adjusted $R$-squared, the Wald statistics, and $p$-values of the models in the box.

The data is a random sub-sample of 7,341 firm-year observations out of the baseline dataset of 71,203 observations. Five other random sub-samples give very similar results.

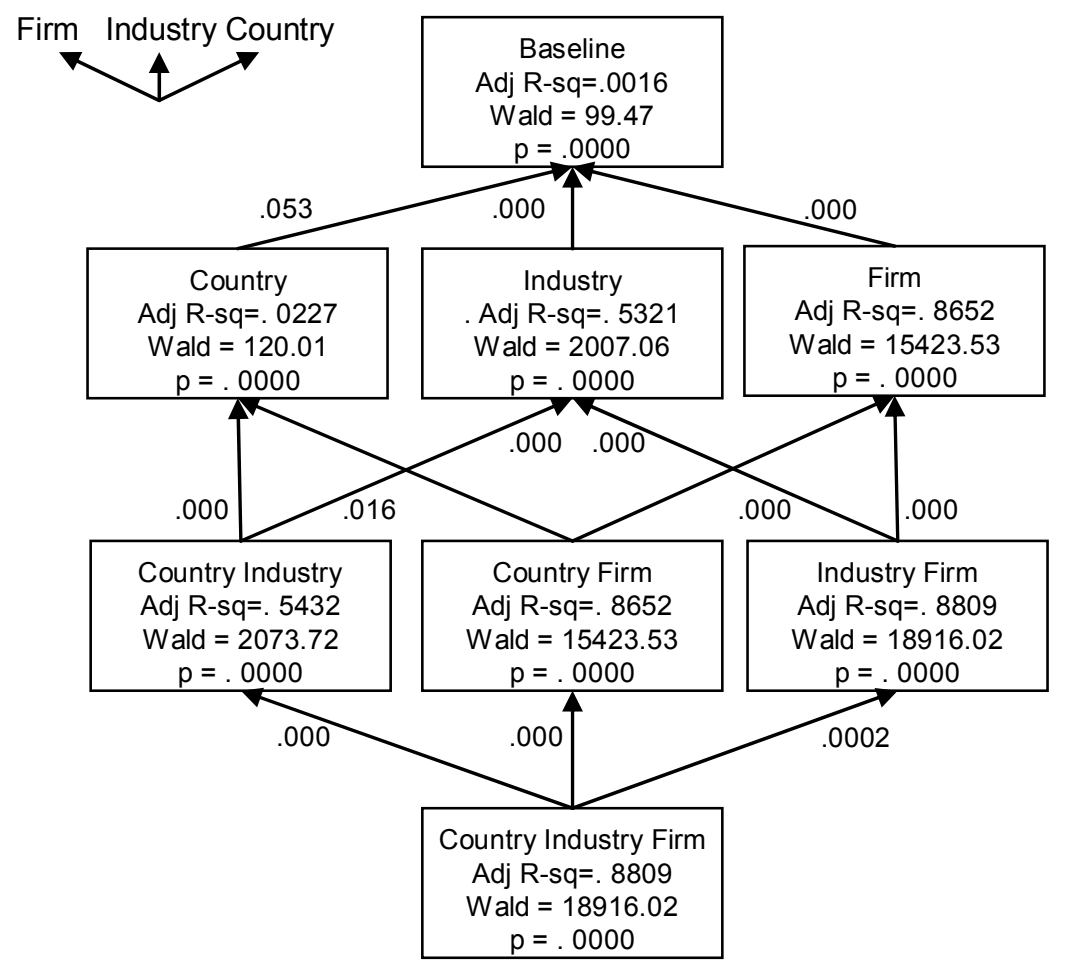

